\title{
Online Workplace
}

This study was designed to explore and describe the relationships between preference for online training and traditional face-to-face training. Included were variables of race, gender, age, education, experience of library employees, training providers, training locations, and institutional professional development policies, etc. in the library context. The author used a bivariate test, KruskalWallis test and Mann-Whitney $U$ test to examine the relationship between preference for online training and related variables.

l $\mathrm{n}$ the era of information explosion, the nature of library and information services makes library staff update their work knowledge and skills regularly. Workplace training has played an important role in the acquisition of knowledge and skills required to keep up with this information explosion. As Richard A. Swanson states, human resource development (HRD) is personnel training and development and organization development to improve processes and enhance the learning and performance of individuals, organizations, communities, and society (Swanson 2001). Training is the largest component of HRD. It helps library employees acquire more skills through continuous learning. Online workplace training is a relatively new medium of delivery. This new form of training has been explored in the literature of human resources development in corporation settings (Macpherson, Elliot, Harris, and Homan 2004), but it has not been adequately explored in university and library settings. Universities are unique settings in which to study HRD, and libraries are unique settings in which to examine HRD theory and practice. In human resource development literature there are studies on participation (Wang and Wang 2004) from the perspective of individual motivation, attitudes, etc.; however, more research needs to be conducted to explore library employees' demographics related to online training in the unique library contexts, such as various staff training and development, as well as training policies. HRD literature includes studies of online learning in formal educational settings (Hiltz and Goldman 2004; Shank and Sitze 2001; Waterhouse 2005), and there are studies on relationships between national culture and the utility of online training (Downey, Wentling, Wentling, and Wadsworth 2005). But there has been very little research conducted in terms of online workplace training for library staff. It is not clear what relationships exist among preferences for online training and demographic variables such as ethnicity, gender, age, educational level, and years of library experience. Due to lack of research in these areas, workplace training in libraries will be less effective if certain ethnic groups, or certain age groups, prefer traditional face-to-face training as libraries move toward online training. The author believes that research should govern library practice. Therefore, it is necessary to research this topic and disseminate the findings. Because of the growth in online training, there is a need to gain a better understanding of these relationships.

\section{Purpose of the study}

The study aims to reveal the relationships between preferences for online or traditional face-to-face training and variables such as ethnicity, gender, age, educational level, and years of experience. It also studies the relationships among preference for online training and other variables of training locations, training providers, training budgets, and professional development policies. The constructs are: the preference for online training was related to demographics, library's training budget, professional development policies, training providers, and the training locations. These factors were included in the research questionnaire. We begin with the research questions, review the current literature, and then discuss the method, results, and need for further research.

\section{Correlational research questions}

1. What is the relationship between ethnicity and online workplace training preferences?

2. What is the relationship of employees' educational levels, age, and years of library experience to online workplace training preferences?

3. How does preference for online workplace training in libraries relate to employee gender?

4. How does preference for online workplace training in libraries relate to training locations, training providers, training budgets, and professional development policies?

5. Do library staff prefer traditional face-to-face training over online training?

\section{Review of the literature}

As stated above, training is the largest component of HRD. The discipline of HRD relies on three core theories: psychological theory, economic theory, and system theory. Swanson (2001) stated:

Connie K. Haley (chaley@csu.edu) is Systems Librarian, Chicago State University Library, Illinois 
Economic theory is recognized as a primary driver and survival metric of organizations; system theory recognizes purpose, pieces, and relationships that can maximize or strangle systems and subsystems; and psychological theory acknowledges human beings as brokers of productivity and renewal along with the cultural and behavioral nuances. Each of these three theories is unique, complementary, and robust. Together they make up the core theory underlying the discipline of HRD (p. 92-93).

Three specific economic theory perspectives are believed to be most appropriate to the discipline of HRD: (1) scarce resource theory, (2) sustainable resource theory, and (3) human capital theory (Swanson 2001). Training is an investment to human capital with valuable returns, but no costs. Wenger and Snyder's study (as cited in Mahmood, Ahmad, Samah, and Idris 2004) states that today's economy runs on knowledge and skills. Thurow's study (as cited in Swanson 2001) states that new industries of the future depend on brain power. Man-made competitive advantages replace the comparative advantage of natural-resources endowments or capital endowments.

In a rapidly changing society, maintaining organizational and individual competence has become a greater challenge than ever before (Hake 1999). Competences include knowledge, skills, and attitudes. Much of the literature focuses on job-related functional competences (Deist and Winterton 2005). Library workplace training is one of the primary methods of investing in human capital and increasing competence for library employees. Training is the process through which skills are developed, information is provided, and attributes are nurtured (Davis and Davis 1998). To increase training participation and efficacy, libraries need to determine employees' preferences for online training or traditional face-to-face training; a resulting high training participation rate would increase the competence of all employees. Library trainers and administrators can encourage nonparticipants to attend training by offering different training sessions (online or face-to-face), and/or by changing training policies and budget allocations. Unlike personality and intelligence, skill competence may be learned; hence it may be improved through training and development (McClelland 1998). Nadler and Tushman (1999) emphasized core competence as a key organizational resource that could be exploited to gain competitive advantage. Core competence was defined as collective learning in the organization, especially how to coordinate diverse production skills and integrate multiple streams of technologies (Prahalad and Hamel 1990). Mezirow (2000) asserted that there are asymmetrical power relationships that influence the learning process (as cited in Baumgartner 2000). Learning more about the relationships may benefit training and learning. In other words, training may be more effective if it is provided in the form preferred by the majority of staff.

As stated above, there is very little research about online workplace training for library staff. Past studies have focused on how to conduct online training for working catalogers (Ferris 2002) or on online teaching for students (Crichton and LaBonte 2003; Hitch and Hirsch 2001). From the design and implementation perspectives, Kovacs (2000) discussed Web-based training in libraries, and Unruh (2000) emphasized problems in delivery of Web-based training. Markless (2002) addressed learning theory and other relevant theories that could be used to teach in libraries. Yet there is a lack of research on the demographics of library staff participation in workplace training and a lack of research on the training preferences of library staff.

\section{Methodology}

The study took place in an online environment. The research activities covered a twenty-day period from April 10 to April 30, 2006. Survey questionnaires and consent forms were posted on the Web.

\section{Select participants}

The survey URL (http:/ / freeonlinesurveys.com/rendersurvey.asp?id=106221) was sent to library staff via library discussion lists along with a consent form including contact information and a brief explanation of the survey's purpose. The surveys were anonymous and confidential. Names, e-mail addresses, and personally identifiable information were not tracked. All participants filled out the survey online. The sample was limited to employees who were at least nineteen years old. Directors and department heads were also welcome to participate.

\section{Instrument}

Data collected for this study included categorical data (i.e., gender and ethnicity) and numeric data (age, years of education, and years of experience). This was an attitudinal survey; hence, the Rensis Likert scale was used for data feedback. Most of the data was quantitative Likert scale, such as the preference for online training, the professional development policy, and the budget allocation for training. Data collection "entailed measuring the attitudes of employees, providing feedback to participants, and stimulating joint planning for improvement" (Swanson 2001). Likert-type scales provide more variation of responses and lend themselves to stronger statistical analysis (Creswell 2005).

It is important to select a well-tested instrument that 
reports reliable and valid data. However, measuring attitudes has been one of the most challenging forms of psychometric measurement (Thorkildsen 2005). Due to a lack of similar studies of libraries' online training, no instruments could be found for this study except the Education Participation Scale (EPS), the Deterrents to Participation Scale (DPS), and the Style Analysis Survey (SAS) instruments. Boshier's forty-item EPS (1974) is reliable in differentiating among diverse groups with varying reasons for participating in continuing education (as cited in Merriam and Caffarella 1999). The EPS is used to find the motivations as to why people participate in continuing education; consequently, the EPS cannot answer all questions of this study. Similarly, the DPS reveals factors of nonparticipation; hence, the DPS cannot be used in this study. And while the SAS is designed to identify how individuals prefer to learn, concentrate, and perform in both educational and work environments (Sloan, Daane, and Giesen 2002), after careful examination, it was found that the SAS was not well-suited to this study. Because surveys are used to collect data and to assess opinions and attitudes (Creswell 2005), the researcher chose to develop a survey that contained about 20 items to assess library staff's opinions and attitudes toward online training.

The survey consisted of three parts: demographic variables, Likert-scale assessment of online workplace training preference, and open-ended questions that were worded to reflect reasons for training preference (see Appendix).

To capture demographic data, participants were asked to indicate their age, years of library experience, years of education (high school/GED $=12$; two years college $=$ 14 ; bachelor's degree $=16$; one master's degree $=18$; two master's degrees = 20; Ph.D/Ed.D = 22+), gender $(1=$ male or $2=$ female $)$, ethnicity $(1=$ Asian/Pacific Islander, $2=$ American Indian, $3=$ African American, $4=$ Hispanic, $5=$ White, non-Hispanic, and $6=$ other). The Likert scale items are designed using a forced-choice Likert scale (Smith 2006), that is, an even number of response options ( 1 = Strongly agree; 2 = Agree; $3=$ Mildly agree; $4=$ Mildly disagree; 5 = Disagree; 6 = Strongly disagree), rather than an odd number (Strongly agree; Agree; Neither agree nor disagree; Disagree; Strongly disagree). A scoring decision is consistently applied in order to have a meaningful interpretation of the scores. Thus, for the Likert scale items, the scaling method is to use high scores to represent stronger resistance to a measured attitude of online training. To insure reliability and validity of scores, the questionnaire was reviewed by an expert in the library field to validate if questions were representative of the library field.

\section{Data collection}

The way a researcher plans to draw a sample is related to the best way to collect data (Fowler 2002). The above sampling approach made it easier for data collection. The author collected data via the Web survey company by paying for survey services on a monthly basis.

The data was collected by the end of April 2006. The total number of participants was $292(n=292)$, of which 260 were valid. Thirty-two participants did not complete the survey; those surveys with missing data were excluded from analysis. Survey results were saved in a text file and then downloaded into SPSS for analysis.

\section{Results and analysis}

Beside general frequency analysis, the Kruskal-Wallis Test was used for six ethnic groups. Since some ethnic groups had small sample sizes, all minorities (48) were merged in one ethnic group. Thus, the Mann-Whitney Test was used for the two ethnic groups-minority and majority. The author also assessed bivariate relationships with preference of online training and other variables.

\section{Frequencies analysis}

Frequencies analysis includes demographics, preference of online training versus face-to-face training, budget, and professional development policies.

Demographics. Eighty-five percent of participants were female, 81 percent were white, 49 percent had one master's degree, and 23 percent had two or more master's degrees. Nearly 70 percent were forty years old or older; 45 percent were fifty years old or older. Thirty-six percent had less than 10 years of library experience (see table 1).

Preference of online training versus face-to-face training. Most participants (87.3 percent) reported that online training was less effective than traditional face-to-face training. Generally speaking, fewer participants (33.9 percent) preferred online training: Strongly agree (3.1 percent), Agree (13.5 percent), and Mildly agree (17.3 percent). More participants (66.1 percent) did not prefer online training: Mildly disagree (28.8 percent), Disagree (28.1 percent), and Strongly disagree (9.2 percent).

Budget. Fifty-five percent of participants somewhat agree their library allocates sufficient budget for training: Strongly agree (8.8 percent), Agree (25.8 percent), and Mildly agree (20 percent).

Professional development policies. Sixty-eight percent of participants somewhat agree their libraries had good professional development policies: Strongly agree (13.5 percent), Agree (30 percent), Mildly agree (24.6 percent). Table 2 shows the frequencies of preference of online training, budget, and policy. 
Table 1. Demographic Characteristics

\begin{tabular}{|c|c|c|}
\hline \multirow{2}{*}{ Characteristics } & \multicolumn{2}{|c|}{ Frequency } \\
\hline & $n$ & $\%$ \\
\hline \multicolumn{3}{|l|}{ Gender } \\
\hline Male & 40 & 15 \\
\hline Female & 220 & 85 \\
\hline \multicolumn{3}{|l|}{ Ethnicity } \\
\hline Asian/Pacific Islander & 22 & 8.5 \\
\hline American Indian & 2 & 0.8 \\
\hline African American & 17 & 6.5 \\
\hline Hispanic & 7 & 2.7 \\
\hline White & 212 & 81.5 \\
\hline \multicolumn{3}{|l|}{ Age } \\
\hline $20-29$ & 23 & 9.4 \\
\hline 30-39 & 54 & 21.2 \\
\hline $40-49$ & 61 & 23.9 \\
\hline $50-59$ & 102 & 40 \\
\hline $60+$ & 14 & 5.5 \\
\hline Missing & 5 & 1.9 \\
\hline \multicolumn{3}{|l|}{ Education } \\
\hline Less than 16 years & 27 & 10.4 \\
\hline 16-17 years/bachelor & 45 & 17.4 \\
\hline $18-19$ years/one master & 128 & 49.4 \\
\hline 20-21 years/two masters & 43 & 16.6 \\
\hline $22+$ years/doctorate & 16 & 6.2 \\
\hline Missing data & 1 & 0.4 \\
\hline \multicolumn{3}{|l|}{ Years of library experience } \\
\hline Less than 10 years & 94 & 35.9 \\
\hline $10-19$ years & 81 & 31.3 \\
\hline 20-29 years & 48 & 16.2 \\
\hline More than 30 years & 37 & 14.3 \\
\hline Missing data & 1 & 0.4 \\
\hline
\end{tabular}

\section{Kruskal-Wallis Test of Ethnicity $(\alpha=.05)$}

In the Kruskal-Wallis test for Ethnicity, to match the total number of 48 minorities, 48 white people were randomly selected from 212. The test was not significantly different. In the Kruskal-Wallis test, Chi-Square is $2.222(\mathrm{df}=4)$ and asymptotic significance was 0.715 , which was greater than the criterion $\alpha=.05$. There was no difference in preference for online training between ethnic groups.
Mann-Whitney U Test Statistics of Ethnicity ( $\alpha=.05)$ The Mann-Whitney test of ethnicity was not significant. Asymptotic significance is $0.81(\mathrm{z}=-.241)$, which was greater than the criterion $\alpha=.05$. There was no difference in preference for online training between the minorities group and the group of white/not Hispanic.

Mann-Whitney U Test Statistics of Gender $(\alpha=.05)$ The Mann-Whitney test of gender was not significant. Asymptotic significance was $0.675(z=-.419)$, which was greater than the chosen $\alpha$ value $(\alpha=.05)$. There was no significant difference in preference for online training between males and females.

\section{Bivariate Analysis $(\alpha=.05)$}

Bivariate correlations were computed (see table 3). Preference for online training was not associated with age, years of education, years of library experience, sufficient training budget, or professional development policy. It makes sense to believe that traditional face-to-face training has better quality than online training. Before the survey analysis, the author expected that younger employees would prefer online training and older ones would prefer traditional face-to-face training due to the older employees' reluctance to change. It was also expected that highly educated employees would prefer online training while less educated ones, with fewer online skills, would prefer traditional face-to-face training. Another assumption was that employees with more library experience would prefer online training while less experienced ones would prefer traditional face-to-face training. The survey showed these assumptions were wrong.

It was also assumed that an insufficient training budget might result in a preference for online training, since online training is more cost effective; and that good professional development policies might result in preference for traditional face-to-face training because it is of better quality than online training. The survey found these assumptions to be false. Training budget and professional development policies were irrelevant to the preference for online training.

However, it was not surprising to find that preference for online training was associated with training providers and training locations, as seen in table 3 .

\section{Discussion}

The exploration of the relationships among these variables revealed that the preference for online training was not related to demographics, budgets, or professional development policies. However, the preference for online training did show a correlation to training providers and locations. It was surprising to discover 
the preference for online training was not associated with ethnicity, gender, age, education, or library experience. It was interesting to note that training budgets and professional development policies were not related to the preference for online training.

Several study hypotheses were confirmed. Library staff preferred traditional face-to-face training as opposed to online training. Although one-third (33.8 percent) of participants preferred (including Mildly agree, Agree, and Strongly agree) online training, only 12.7 percent of participants thought that online training was more effective than traditional face-to-face training. On the other hand, the majority ( 80 percent) preferred online training when the training was held out of state; 56.2 percent preferred online training when it was held in state. The study concluded that online training was preferred if the training locations required participants to travel great distances from the library.

Of the participants, 63.1 percent preferred online training when the training was provided by a vendor. Some participants did not think face-to-face contact was important for vendor training. This finding suggests that online training is a better choice for vendor training. Fifty-five percent preferred online training when it was provided by an association/organization. Association/ organization trainers should consider a combination of online and traditional face-to-face training to meet the needs of the majority. Online training can be provided for some specific tasks, and supplemented by face-to-face training for others. The following are survey summaries of key reasons to use online and traditional training, along with suggestions from the survey participants.

\section{The main reasons to use online training}

- flexible (allows more people from one worksite to participate)

- saves time

- eliminates travel cost

- generally lower training costs

- ease of access (able to have handson practice with a technology and software program, able to refer back to supplemental materials, able to obtain wider range of training, appropriate to give general overviews in preparation for more indepth face-to-face training)

- convenient (have some control over one's time, attend training from the comfort of home or office rather than having to drive somewhere and sit through a presentation, fits easily into a busy schedule, and self-paced in asynchronous online training)

\section{The main reasons to use face-to-face training}

- Questions and answers: able to ask questions and discuss answers, see immediate feedback, questions others are asking may include some that you didn't think of, and problems solved directly

- Networking with peers: face-to-face training allows for serendipitous networking opportunities, you have the option of personal conversations with trainers as well as social opportunities to meet other professionals, it is hard to meet people and make friends through an online training, get out of the library once in awhile, find out what experiences staff from other departments or libraries are having

- Better communication and interaction: have personal interaction with instructors and participants, share ideas and experiences with others, enjoy discussions and diversity of personal opinions that come from face-to-face training

- Learn efficiently and effectively: learn from othersnot just the instructor, get more out of real training, easy to get disinterested if no face-to-face contact, learn better from an instructor

- Technology barrier: sometimes technology can get in the way of training, some online training was poorly designed, online classes took forever to load and two seconds to read the whole page.

\section{Suggestions to improve library workplace training}

Administrative support. The most important factor is having library administrators who support training and encourage staff at all levels to attend training. Provide workshops for professional librarians and civil service workers that relate to their work, and give them release time for training. Library administrators must understand the importance of training and develop training policies with a commitment toward staff development.

Table 2. Frequencies of Preference of online training, budget, and policy

\begin{tabular}{llll} 
& \multicolumn{2}{l}{ Frequency } & \\
Descriptor & Mean* $^{*}$ & Median* $^{*}$ & Std. Deviation \\
\hline Preference of online training & 3.93 & 4 & 1.281 \\
Budget & 3.45 & 3.0 & 1.550 \\
Policy & 3.0 & 3.0 & 1.437 \\
\hline
\end{tabular}

$1=$ Strongly agree; 2 = Agree; 3 = Mildly agree; 4 = Mildly disagree;

$5=$ Disagree; $6=$ Strongly disagree 
Table 3. Bivariate correlations with preference of online training $(\alpha=.05)$

\begin{tabular}{ll} 
Variables & Preference of online training \\
\hline Age & .980 \\
Education & .507 \\
Library experience & .259 \\
Budget & .858 \\
Prof. development policies & .280 \\
Training provider & \\
$\quad$ Vendors & $<.01^{*}$ \\
Associations/org. (ALA, OCLC, etc.) & $<.01^{*}$ \\
Lib. consortia & $<.01^{*}$ \\
Library/institution & $<.01^{*}$ \\
Training location & \\
Out of state & $<.01^{*}$ \\
In state & $<.01^{*}$ \\
In town & $<.01^{*}$ \\
In house & $<.01^{*}$ \\
\hline
\end{tabular}

* Significant at $\alpha=.05$

Library administrators must plan and design training infrastructures for core competence and cumulative learning, instead of spontaneous one-shot training for new products or systems.

More training. Many participants expressed their desire for more training. Training not only increases their knowledge and skills needed for their job, but also provides opportunities to network with colleagues. More face-to-face and technical hands-on training are needed since many librarians felt left out of the technology loop. They think that maintaining a current view of developments in technology is difficult. More online training is needed, both asynchronous and synchronous. Asynchronous training is good for self-paced training, which is preferred by many survey participants, while some enjoy online Webcasts of seminars and workshops for better interaction. It is hoped that state libraries will provide online streaming videos about various topics for academic, private, and public library staff.

More funding. Make more funding available for library workplace training. The training budget should not be the first thing cut when budgets get tight.

A combination of online and traditional face-to-face training. Walton (1999) notes that we must ensure we learn and grow. We may learn and grow by participat- ing workplace training. Training programs should be built into strategic HRD plans that will best fit employees' learning preference. This study shows that online training works well with basic informational topics and most technology topics (databases, searching, or Web-related technologies). Certain simple topics were more appropriate for online training, such as a vendor's product and procedural training. Some topics do not translate well into online training, however, such as how to conduct storytimestopics that require a lot of interaction between participants. Difficult topics need traditional training for direct answers from the instructor. Topics that need in-depth discussion should be provided with traditional training. In other words, provide basic trainings online and save face-to-face training for more difficult topics.

\section{Future research}

Future research should focus on new learning needs, how people interact with technology, and how people learn in an online environment. More research is needed for a variety of online training. In this study, the generic term "online training" was used. Future study needs to expand the term "online training" to static asynchronous online training and interactive synchronous online training. Static online training includes text-only static, and textgraphic static with or without voice. Interactive online training includes voice-only interactive, and voice-video interactive with ability to ask and answer questions in real time.

As time goes by, more people will have taken online training and will be more comfortable with it. As more people have online training experience, their attitudes toward online training may change. Further research should examine and measure library staff's preference for a variety of online training. In addition, participants should be surveyed by grouping experienced online trainees and non-experienced online trainees. Finally, studies may be conducted to survey library staff in other countries to compare their preferences with those of their U.S. peers.

The goal of this study is to provide helpful information for department heads, supervisors, and library human resources staff to assist them in determining the types of training that will be most effective to meet train- 
ing needs. The author hopes this study also provides useful information to all library employees who attend training or workshops, including civil service personnel and librarians, and that this study will be utilized for further research on library training and, in turn, that research will make more contributions to the workplace training literature of libraries and other professions.

\section{Acknowledgements}

The author thanks Lorraine Lazouskas, John Webb, Judith Carter, and the copy editors at ALA production services for their assistance and valuable input on this manuscript.

\section{Bibliography}

Baumgartner, L. M. 2000. Preface. In L. M. Baumgartner and S. B. Merriam (eds.), Adult learning and development: Multicultural stories. Malabar, Fla.: Krieger Publishing.

Creswell, J. W. 2005. Educational research: Planning, conducting, and evaluating quantitative and qualitative research. 2nd ed. Upper Saddle River, N.J.: Pearson Merrill Prentice Hall.

Crichton, S., and R. LaBonte. 2003. Innovative practices for innovators: Walking the talk; Online training for online teaching. Educational Technology \& Society 6, no. 1: 70-73.

Davis, J. R., and A. B. Davis. 1998. Effective training strategies : A comprehensive guide to maximizing learning in organizations. San Francisco: Berret-Koehler.

Deist, F. D., and J. Winterton. 2005. What is competence? Human Resource Development International 8, no. 1: 27-46.

Downey, S., R. M. Wentling, T. Wentling, and A. Wadsworth. 2005. The relationship between national culture and the usability of an e-learning system. Human Resource Development International 8, no. 1: 47-64.

Ferris, A. M. 2002. Cataloging internet resources using MARC21 and AACR2: Online training for working catalogers. Cataloging and Classification Quarterly 34, no. 3: 339-353.

Fowler, F. J. 2002. Survey research methods. 3rd ed. Thousand Oaks, Calif.: Sage.

Haley, C. K. 2006. Who participates in online workplace training in libraries? Survey results retrieved April 25, 2006, from http:/ / freeonlinesurveys.com/viewresults.asp?surveyid=183507.

Hake, B. J. 1999. Lifelong learning in late modernity: The challenges to society, organizations, and individuals. Adult Education Quarterly 49, no. 2: 79-90.

Hiltz, S. R., and R. Goldman, eds. 2004. Learning together online. Mahwah, N.J.: Lawrence Erlbaum Associates.
Hitch, L. P., and D. Hirsch. 2001. Model training. Journal of Academic Librarianship 27, no. 1: 15-19.

Kovacs, D. K. 2000. Designing and implementing web-based training in libraries. Business and Finance Division Bulletin 113 (winter): 31-37.

Macpherson, A., M. Elliot, I. Harris, and G. Homan. 2004. E-learning: reflections and evaluation of corporate programme. Human Resource Development International 7, no. 3: 295-313.

Mahmood, N. H. N., A. Ahmad, B. A. Samah, and K. Idris. 2004. Informal learning of management knowledge and skills and transfer of learning among head nurses. In Human Resource Development in Asia: Harmony and partnership, R. Moon, A. M. Osman-Gani, K. Shinil, G. Roth, and H. Oh, eds. Seoul: The Korea Academy of HRD.

Markless, S. 2002. Learning about learning rather than about teaching. Retrieved July 5, 2007, from http:/ /www.ifla.org/IV/ ifla68/papers/081-119e.pdf.

McClelland, D. 1998. Identifying competencies with behavioralevent interviews. Psychological Science 9, no. 5: 331-339.

Merriam, S. B., and R. S. Caffarella. 1999. Learning in adulthood. San Francsico: Jossey-Bass.

Mezirow, J. 2000. Learning to think like an adult: Transformation theory; Core concepts. In Learning as transformation: Critical perspectives on a theory in progress, J. Mezirow and Associates, eds. San Francisco: Jossey-Bass.

Nadler, D. A., and M. Tushman. 1999. The organization of the future: Strategic imperatives and core competencies for the 21st century. Organisational Dynamincs 27, no. 1: 45-48.

Prahalad, C. K., and G. Hamel. 1990. The core competence of the corporation. Harvard Business Review 68, no. 3: 79-91.

Shank, P., and A. Sitze. 2004. Making sense of online learning. San Francisco: Pfeiffer.

Sloan, T., C. J. Daane, and J. Giesen. 2002. Mathematics anxiety and learning styles: what is the relationship in elementary preservice teachers? School Science and Mathematics 102, no. 2: 84-87.

Smith, J. T. 2006. Applied categorical data analysis. Lecture presented in spring 2006 at Northern Illinois University, DeKalb.

Swanson, R. A. 2001. Foundations of human resource development. San Francisco: Berrett-Koehler.

Thorkildsen, T. A. 2005. Fundamentals of measurement in applied research. Boston: Pearson Education.

Unruh, D. L. 2000. Desktop videoconferencing: The promise and problems of delivery of web-based training. Internet and Higher Education 3, no. 3: 183-199.

Walton, J. 1999. Strategic human resource development. Harlow, England: Pearson Education.

Wang, G. G., and J. Wang. 2004. Toward a theory of human resource development learning participation. Human Resource Development Review 3, no. 4: 326-353.

Waterhouse, S. 2005. The power of elearning: The essential guide for teaching in the digital age. Boston: Pearson Education. 


\section{APPENDIX. Questionnaire}

\section{Part I.}

1. Gender

$\checkmark$ Male

$\square$ Female

2. Ethnicity
- Asian or Pacific Islander
African American
White, non-Hispanic
American Indian
$\square$ Hispanic
$\square$ Other

3. Please indicate the year of your birth:

4. Please indicate years of education:

5. Please indicate years of library experience:

\section{Part II.}

For Questions 6-16, please read each item and check the response that best matches your degree of agreement/disagreement: $(1=$ Strongly agree; $2=$ Agree; $3=$ Mildly agree; $4=$ Mildly disagree; $5=$ Disagree; $6=$ Strongly disagree $)$

6. If training is provided by library vendors such as EBSCO or Blackwell, I would prefer that it be offered online rather than face-to-face.

7. If training is provided by associations/organizations such as ALA and OCLC, I would prefer that it be offered online rather than face-to-face.

8. If training is provided by library consortia, I would prefer that it be offered online rather than face-to-face.

9. If training is provided by your institution or library, I would prefer that it be offered online rather than face-toface.

10. If training location is out of state, I would prefer that it be offered online rather than face-to-face.

11. If training location is in-state, I would prefer that it be offered online rather than face-to-face.

12. If training location is in town, I would prefer that it be offered online rather than face-to-face.

13. If training location is in-house, I would prefer that it be offered online rather than face-to-face.

14. My library allocates sufficient budget for training (may include online training).

15. My library has good professional or staff development policies.

16. Generally speaking, I prefer online training rather than face-to-face training.

\section{Part III.}

17. State reasons for your preference of traditional face-to-face training.

18. State reasons for your preference of online training.

19. Please make suggestions to improve library workplace training.

20. Do you think that online training is less effective than traditional face-to-face training? Yes__ No 